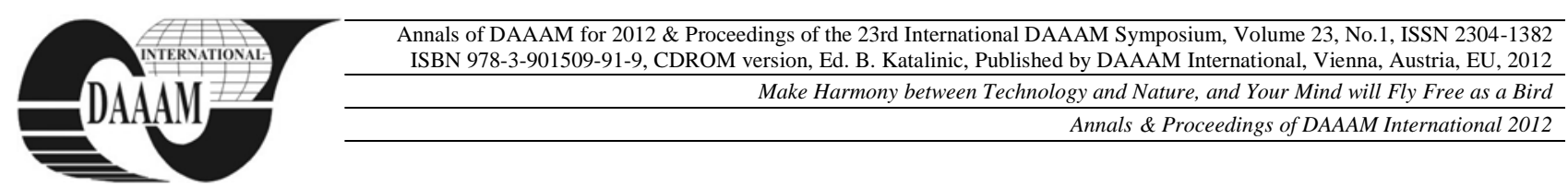

\title{
STUDY OF TECHNOLOGICAL OPTIONS TO LOAD HAMMER MILL FOR GRINDING COAL
}

\author{
DEMIAN, M[ihai]; DEMIAN, G[abriela] \& SACEANU, C[onstantin]
}

\begin{abstract}
The maintenance of a power plant it is an important issue for all energy producers. A vulnerable point of a power plant is coal grinding mill. The main objectives of the investigation is to increase the lifetime of the coal grinding mill This paper presents several technological options to load hammer from coal grinding mill. The experimental technological variants analyzed are thermal spraying and welding load. This paper presents the method of thermal spraying in plasma jet with ceramic powder and weld load in two cases. For the obtained samples, were made structural examinations and hardness tests.

The paper shows a technological variant that are applied to load hammers from a coal grinding mill to increase the durability. The hardness of the deposited layers (which are the active surface) increases very much, about three times after the technological variant is used.
\end{abstract}

Keywords: thermal spraying, plasma, ceramic powder, hammers coal grinding mill, hardness HV5

\section{INTRODUCTION}

In the real exploatation of the installations, aggregates or equipment are found problems that in design elements that were not taken into account.

Complex problems that are in the thermo power plants, can appear as an interdisciplinary problem, (mechanical, physics, chemistry, metallurgy, technology, etc.), which results as frequent interruptions in operation. Trouble-free operation of a product until exhaustion of physical or moral, is a goal of any manufacturer. Uninterrupted operation of power plants is important issue for each local community or trader using product as hot water and / or steam.

Equipment typically used in power plants are designed for long operational life time (100,000 hours) but are dependent precisely the operating conditions that leading to the properties changes of the active elements of equipment and determine to a deterioration of them and hence the failure which cause the entire system crash.Equipment which is used to heavy, intense and variable demands in a power plant is coal grinding mill, where hammers wear out relatively quickly and are replaced periodically. It's called aging process standards and product durability.

Replacing the mill hammers varies primarily due to coal properties, impurities contained therein and of course the operating parameters to die.

For a good maintenance of the mill in operation there are high costs and is therefore necessary and justified to carry out research for the purpose of increasing the life of the hammer mill for grinding coal to give some operational parameters of the mill.

There are several solutions to increase sustainability hammer mill grinding of coal. The easiest way is to choose another material hammers but this would mean additional expenses that it should abandon the existing stock hammers and costs for production and acquisition of new hammers manufactured manufacturer would not cost very high.

Welding technologies have been developed very much and the result was an increase in reliability of welded structures, which is due by using filler materials (ferrous and nonferrous alloys) with mechanical, technological and operational higher as electrodes or wires.

Using materials with superior characteristics, with the appropriate heat treatment regimes and appropriate technology, permit to obtain the desired phase and structural transformations in the joint and in heat affected zone ZIT. Preparation and coal dust burning plant contain several elements which participate in the preparation of coal dust that is made with six mills hammer and a fan [1]. Crushed coal mill is designed to dry and ground coal. Fan blades and hammers are used in grinding mill.

Cast steels are used for parts which requiring high strength and toughness, they are much better in economically and technologically than other steels.

Casting properties are special alloy steels for OT 40, OT 70 (STAS $600-82$ ) or $200-400 \mathrm{~W}-550 \mathrm{~W} \ldots .340$ as ISO 3755-1995, but are used for cast steels are able to weld (allied only with preheating to $300-500{ }^{\circ} \mathrm{C}$ ).

The European standard used is SREN 1090 -3/2008. Following the preparation plant and associated coal dust burning a mill was a short duration of operation of the mill because the hammers used for grinding wear quickly.

The maximum operating under normal conditions of a hammer was 250 hours, [2].

The life of these hammers is relatively low, the extension of traditional methods of charging welding active parties.Among the methods used can remember 
MIG-MAG welding, MAG, each in several variants. In order to complete loading welding technology hammer mill, several options were discussed of charging by welding technology.

Simple load with welding procedures, requiring relative high filler consume and great depth training on the material which is subjected to welding.

To reduce the amount of deposited metal layers deposited and increased hardness of metal layers deposited, were tested four additional charge technology of thermal spray with metal powders and ceramic powders mixed and welding load with complex hard alloys.

The researchers are made on thermal method with spraying in plasma jet using ceramic powder and weld load in two variants.

This kind of research on the material from hammers coal grinding mill as OT 40, OT 70 (STAS 600-82) or 200-400W-550W ... .340 as ISO 3755-1995 are only few in the specialized literature[2].

So, the results and the technical solution for this material, represent new way to improve the hardness of the hammers surface from a coal grinding mill.

Issues raised in the future are related to comparison of four methods of thermal spraying and welding load, there were two variants for each type of coating, thermal spraying in plasma jet with metal powder and thermal spraying in plasma jet with ceramic powder. For each method, there will be made tests to determine the wear.

Future research will be to achieve in laboratory wear tests and endurance (in running) for industrial components from power plant.

Abrasive wear of complex alloys deposited on coal grinding hammers can be described as a process of destruction of surface layer (deposit) at the mechanical interaction with other solids (coal) which acts as external load, both bodies have a relative motion.

Abrasive wear test is based on evidence submitted wear layers tough on a specialized machine and the following stages of testing and evaluation:

- Preparation and identification of materials;

- Review and record the initial state;

- Application set of requests;

- Analysis and measurement of parameters after the trial;

- Processing and interpretation of results.

Hammers to crush coal loaded with a variant alloys as in a technical specifications will be installed in a coal mill row which is subject to most abrasive wear of the coal and tailings.

Hammers will be weighed and marked before introduction into the mill and then subjected to endurance under normal mill operation for production of raw material in the boiler furnace combustion. Weight loss measurements will be made by measuring the final weight after stopping the mill.

\section{TESTS AND RESULTS}

Experimental technological variants with thermal spraying and welding load is divided into two main categories, thermal spraying in plasma jet with metal powder and thermal spraying in plasma jet with ceramic powder.

The process of thermal spraying in plasma jet with metal powder was analyzed in the context of previous research.

For thermal spraying in plasma jet with ceramic powder process, samples marking were done with M (M3 and M4):

- M3 for thermal spraying in plasma jet with ceramic powder METCO 105NS (98 + Al2O3) and MAG welding process (135) with filler wire and gas FLUXOFIL M58 and gas M21, (Materials Guide, 2008).

- M4 for thermal spraying in plasma jet with ceramic powder METCO 105NS (98+Al2O3) and MAG welding process (135) with filler wire FILEUR AMC 60 and gas M21.

Macro-microscopic examinations and tests hardness HV5 were made in areas characteristic of welded joints according to EN 1321.

Minimum and maximum total thickness of deposits (material + thermal spray coating applied to alloys) determined by measurements of optical microscope equipped MeF2 are shown in Table 1.

\begin{tabular}{|c|c|c|c|}
\hline \multirow{2}{*}{$\begin{array}{c}\text { Sample } \\
\text { marking }\end{array}$} & \multicolumn{2}{|c|}{$\begin{array}{c}\text { Total thickness of layers deposited } \\
{[\mathrm{mm}]}\end{array}$} & $\begin{array}{c}\text { Average } \\
\text { Values } \\
{[\mathrm{mm}]}\end{array}$ \\
\cline { 2 - 3 } & minimal Values & Maximum Values & 9,42 \\
\hline M3 & 3 & 8,90 & 11,37 \\
\hline M4 & 4 & 9,63 & \multicolumn{2}{c}{} \\
\hline
\end{tabular}

Tab. 1. Total thickness of layers deposits

Replacement of buffer layers frequently made by welding alloys Fe-C alloy and super alloys of Ni-based mixed metal powder (Ni-Al) or ceramic powder melted, was based on the achievement of layers with homogeneous structure and thickness layer relatively equal [3].

\begin{tabular}{|c|c|c|c|}
\hline \multirow[b]{2}{*}{$\begin{array}{l}\text { Sample } \\
\text { marking }\end{array}$} & \multicolumn{3}{|c|}{ Sprayed layer thickness $[\mu \mathrm{m}]$} \\
\hline & $\begin{array}{l}\text { Individual Values, } \\
\qquad g\end{array}$ & $\begin{array}{l}\text { Medium } \\
\text { Values, } \bar{g}\end{array}$ & $\begin{array}{c}\text { Mean } \\
\text { square } \\
\text { deviation } \\
\Delta_{X}\end{array}$ \\
\hline M3 & $\begin{array}{c}128 ; 129 ; 128 ; \\
131 ; 136 ; 128 ; 130 \\
130 ; 132 ; 133\end{array}$ & 130,5 & 2,59 \\
\hline M4 & $\begin{array}{c}140 ; 142 ; 132 ; \\
135 ; 138 ; 140 ; 141 ; \\
139 ; 138 ; 137\end{array}$ & 138,2 & 2,97 \\
\hline
\end{tabular}

Tab. 2. Sprayed layer thickness 
Spray deposition process of thermal plasma jet used in conducting layers of non-alloy steel casting inserted layer thickness provided in Table 2 .

Deposited layer thickness measurements were made with machine Leptoskop-Poket

Analyzing the values of layers thickness is noted that the $\mathrm{M} 3$ and $\mathrm{M} 4$ samples deposited $\mathrm{Al}_{2} \mathrm{O}_{3}$ ceramic powder layer thicknesses varying between 128 and $131 \mu \mathrm{m}$ (the sample M3) and between 137 and $142 \mu \mathrm{m}$ (the sample M4) with standard deviation $\Delta_{\mathrm{x}} 2,59$ and 2,97.

Macroscopic examination conducted outlining the cross-sectional samples of deposits made in versions 3,4 (Figures 1 and 2) [5,6].

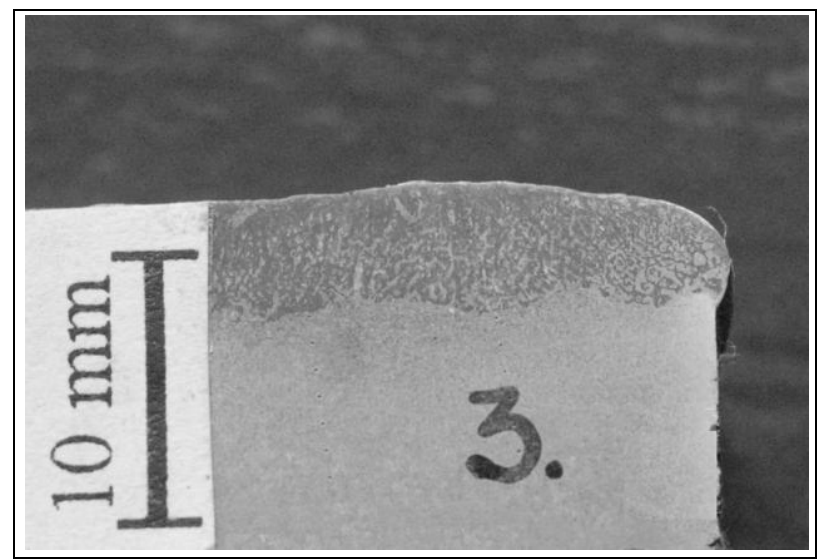

Fig. 1. Sample M3 (attack concentrated ferric chloride)

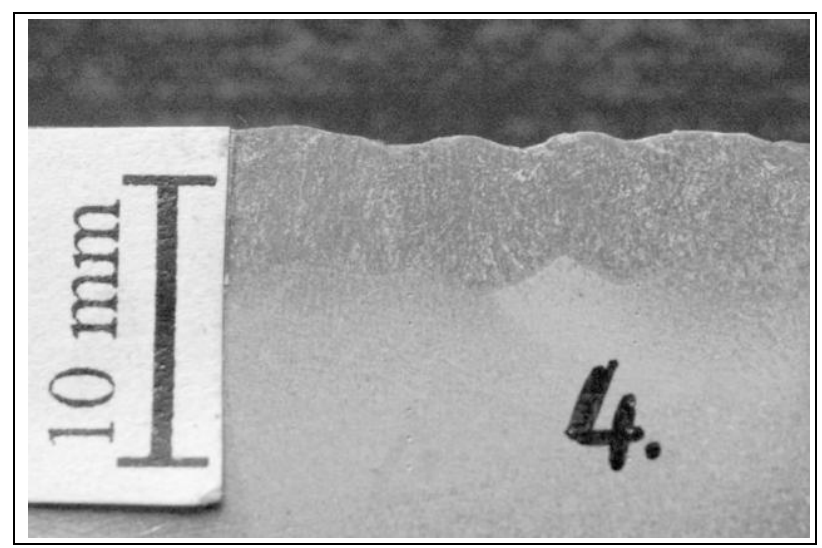

Fig. 2. Sample M4 (attack concentrated ferric chloride)

Examinations conducted on both the outer surface of the deposits and their cross section revealed welding defects.

Microscopic examinations of areas characteristic of joints (MB - basic material, ZIT - heat affected zone, MD - material deposited) made highlighting a structure as:

In all metal core samples M3 and M4-there are with ferrite perlitic casting structure with grob ferrite and in network (Figures 3 and 4), [4].

Metals deposited (MD) of samples M3 and M4 have hard martensitic structures with specific complex carbides of $\mathrm{Cr}$, Mo and fine particles of alumina $\left(\mathrm{Al}_{2} \mathrm{O}_{3}\right)$ dispersed in hard core (Figure 5).

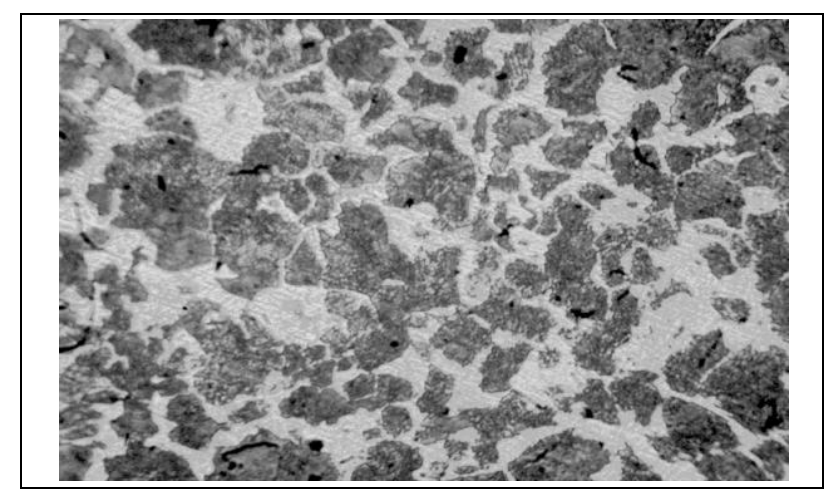

Fig. 3. Metal base (MB) attack (Nital 2\%, $100 \mathrm{x})$

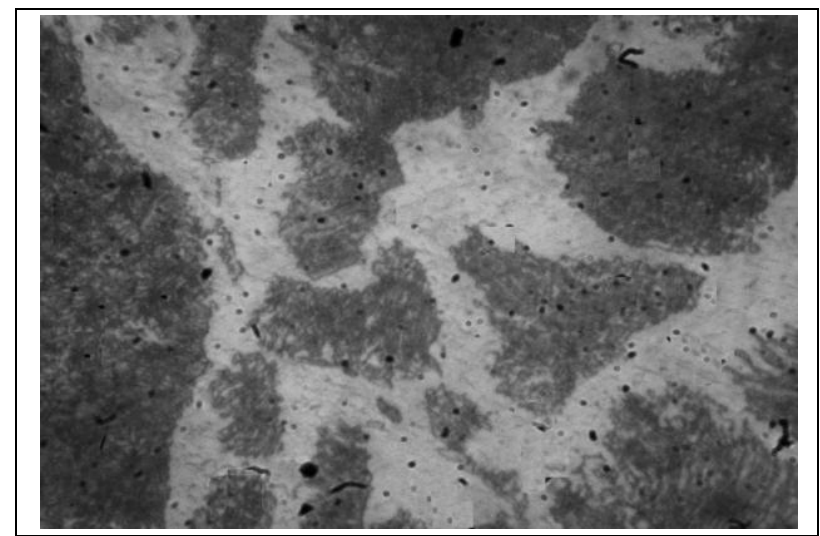

Fig. 4. Metal base (MB) attack (Nital 2\%, $500 \mathrm{x})$

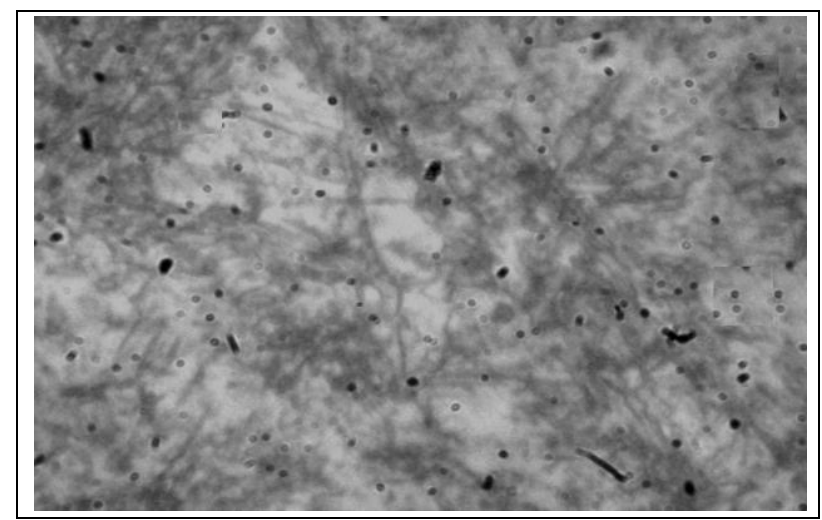

Fig. 5. Sample M3, Metal deposited (MD)(ferric chloride attack, 500 x)

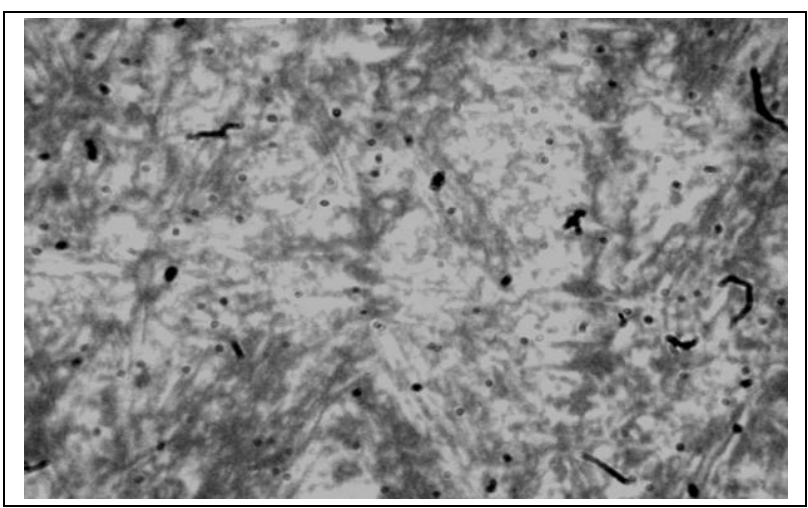

Fig. 6. Sample M4, Metal deposited (MD)(ferric chloride attack, 500 x)

The heat affected zones (ZIT) were detected in all samples perlito-ferritic structure with ferrite network (Figures 7 and 8) 


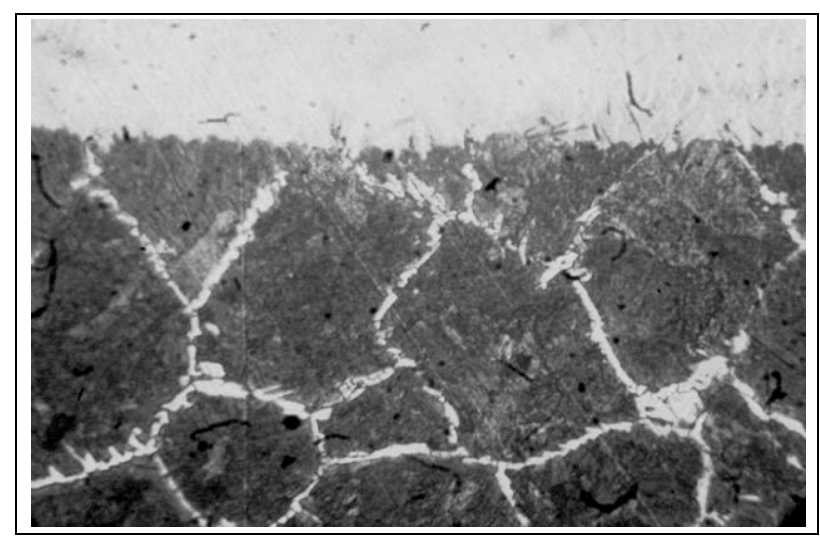

Fig. 7. sample M3, ZIT (ferric chloride attack, $500 \mathrm{x}$ )

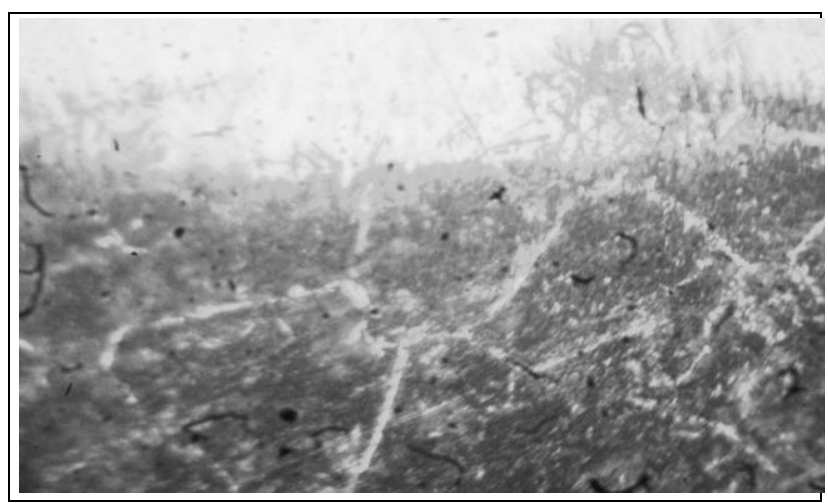

Fig. 8. sample M4, ZIT (ferric chloride attack, $500 \mathrm{x}$ )

\begin{tabular}{|c|c|c|c|c|c|c|c|c|}
\hline & \multicolumn{6}{|c|}{ Hardness HV5 } & \multirow{2}{*}{\multicolumn{2}{|c|}{$\begin{array}{c}\text { Estimator } \\
\Delta \mathrm{HV} 5[\%]\end{array}$}} \\
\hline & \multicolumn{2}{|c|}{ MB } & \multicolumn{2}{|c|}{ ZIT } & \multicolumn{2}{|c|}{ MD } & & \\
\hline & $\begin{array}{l}\Xi \\
\frac{\Xi}{\not} \\
\frac{\dot{\sigma}}{>}\end{array}$ & 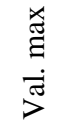 & $\begin{array}{l}\Xi \\
\stackrel{\Xi}{\Xi} \\
\frac{\pi}{>}\end{array}$ & 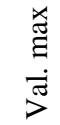 & $\begin{array}{l}\text { 范 } \\
\frac{\dot{\sigma}}{>}\end{array}$ & 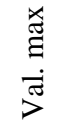 & MD & $\begin{array}{l}\text { ZIT- } \\
\text { MD }\end{array}$ \\
\hline 0 & 2 & 3 & 4 & 5 & 6 & 7 & 8 & 9 \\
\hline M3 & 221 & 244 & 241 & 284 & 584 & 623 & 6,26 & 22,18 \\
\hline M4 & 199 & 223 & 216 & 239 & 584 & 677 & 13,73 & 16,74 \\
\hline
\end{tabular}

Tab. 3. Hardness values

Joints areas M3 and M4 show the hardness values which are summarized in Table 3.

Also in Table 3 is passed the hardening values of the local estimator [7].

Analyzing $\triangle \mathrm{HV} 5$ estimator values are found that in all samples analyzed, these do not exceed $50 \%$, as per the material deposited (MD) and between MB and ZIT there are no local hardening tendencies and thus possibilities of developing brittle-type fracture, although that the submitted materials appeared very high hardness, namely:

The submitted samples M3 and M4 variants 3 and 4 minimum 701 and maximum 841 HV5 $[8,9]$.

\section{CONCLUSIONS}

Analyzing the tests on samples M3 and M4 [10], can draw the following conclusions:
Examinations done on the outer surface of the deposits as well as their cross section revealed no welding defects.

At the M3 and M4 samples deposited $\mathrm{Al}_{2} \mathrm{O}_{3}$ ceramic powder layer thicknesses varying between 128 and 131 $\mu \mathrm{m}$ (the sample M3) and between 137 and $142 \mu \mathrm{m}$ (the sample M4) with standard deviation $\Delta_{\mathrm{x}}, 2,59$ and 2,97.

In all metal core samples M3 and M4 there are with ferrite perlitic casting structure with grob ferrite and in network

Metals deposited (MD) on samples M3 and M4 have hard martensitic structures with specific complex carbides of $\mathrm{Cr}$, Mo and fine particles of alumina $\left(\mathrm{Al}_{2} \mathrm{O}_{3}\right)$ dispersed in hard core.

In all samples in the heat affected zones (ZIT) were detected structures as ferrite with perlitic in network.

At the submitted samples M3 and M4 in variants 3 and 4 there is very high hardness values, between minimum 701 and maximum 841 HV5.

Issues raised in the future are related to comparison of four methods of thermal spraying and welding load, there were two variants for each type of coating, thermal spraying in plasma jet with metal powder and thermal spraying in plasma jet with ceramic powder. For each method, there will be made tests to determine the wear.

Surface wear that occurs during operation of technical systems is due to contact and relative movement between the elements and give rise to surface tension. This leads to energy and material losses due to friction, but also changes as a result of wear items. Laboratory wear tests and endurance (in running) will be made on industrial components from thermal power plant.

\section{REFERENCES}

[1] Popa, T., Muşatescu, V., \& Marinuş, L. (1985) - Thermal power plants installations. - Didactic and Pedagogical Publisher, pp. 98104, Bucharest, Romania

[2] Saceanu, C., (2010), Studys regarding attitude of mill hammers in exploitation, Annals of Daaam for 2010 and proceedings, Publisher: Daaam International Vienna, ISSN: 1726-9679 Vienna, Austria

[3] Voda, V. (1997) - Sampling plans to check reliability. Quality Tribune nr.9/1997, Romania

[4] Truşculescu, M., Demian, M. (2006), Materials Handbook, Structural Metallurgy, Vol. I, Politehnica Publisher, ISBN: 978973-625-356-0, Timişoara, Romania

[5] Truşculescu, M., Tache A. M., Mitelea, I. \& Budău, V. (1977) Study metals. Laboratory techniques. Facla Publisher, Timişoara, Romania

[6] http://www.asro.ro, (1998). Collection of standards commented vol I. Material tests. Methods of examination of the structure. Romanian Institute for Standardization, Bucharest, Romania

[7] http://www.asro.ro, (1988) Mechanical tests of metals. Romanian Institute for Standardization, STAS 6967-88, Romania

[8] http://www.welding-alloys.com, (2008) Hardfacing catalogue, Welding Alloys Group - Germany

[9] http://www.sulzer.com, (2008) Materials Guide, Sulzer Metco, The Coatings Company, USA

[10] Anghel, I. (1993) - Alloyed steels welding. Technical Publisher. ISBN: 973-31-0507-4, Bucharest, Romania 